\title{
PENGARUH IKLAN TELEVISI TERHADAP BRAND AWARENESS SHOPEE DI PT. SHOPEE INTERNATIONAL INDONESIA JAKARTA
}

\author{
Nurdina Sahab \\ STIE UniSadhuGuna Business School Jakarta, Indonesia \\ Nurdina.Sahab@ubs-usg.ac.id
}

\section{Abstract}

This study aims to determine whether there is an influence of Shopee television advertising on Shopee brand awareness at PT. Shopee International Indonesia Jakarta. This research was conducted in July 2018 through the help of Google Form (online questionnaire). The population in this study is Shopee consumers in TB Simatupang office area. Sampling using purposive sampling technique. Research data was obtained through an online questionnaire about television advertising and brand awareness for 100 respondents. The instrument testing method used is testing validity and reliability. Data analysis techniques used are quantitative descriptive techniques, simple linear regression analysis and $t$ test. The results showed that in television advertising has an influence on Shopee brand awareness.

Keywords: television advertising; brand awareness

\section{Pendahuluan}

Bisnis e-commerce di Indonesia melaju pesat dan persaingan yang semakin ketat di pasar situs online harus memahami orientasi calon konsumen terhadap merek suatu produk untuk memaksimalkan niat pembelian online pelanggan yang mengarah pada peningkatan penjualan online. Salah satu situs jual beli online di Indonesia yang sedang berkembang adalah Shopee. Pada bulan Maret-Oktober tahun 2017, selisih jumlah search interest antara Shopee dan pesaingnya yaitu Elevenia cukup besar. Namun sampai dipenghujung tahun 2017, Shopee masih berada diposisi ke empat. Sebagai salah satu pemain "muda", banyak upaya yang dilakukan Shopee untuk memperkecil jarak dengan e-commerce lain yang sudah bermain lama di Indonesia. Mulai dari kampanye, penguatan pada komunitas penjualnya, dan strategi lainnya. Dari paparan info di atas, bisa dilihat juga beberapa lonjakan search interest (minat mencari) dari beberapa e-commerce.

\section{Gambar 1}

\section{Pertumbuhan Dan Persaingan Kunjungan Situs E-Commerce Indonesia Di Tahun 2017}

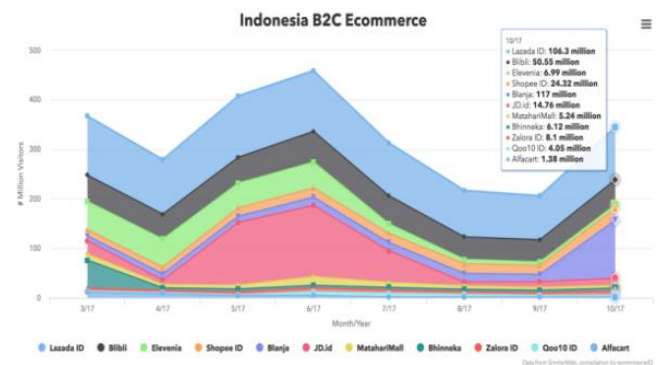


Salah satu cara agar Shopee dapat membangun dan mepertahankan kesadaran merek atau brand awareness, terlebih jika menginginkan brandnya bertahan dalam kategori top brand, dibutuhkan sebuah promosi.

Shopee adalah salah satu dari perusahaan e-commerce yang giat melakukan promosi iklan melalui media televisi. Iklan dengan pesan-pesan edukasi secara konsisten dan dengan cerita atau tema iklan Shopee selalu up to date mengikuti trend yang selalu berganti. Adanya berbagai versi iklan pada promosi-promosi Shopee pasti akan sangat berhubungan kuat dengan brand awareness baik konsumen akan sadar maupun mengingat sebuah merek.

\section{Metode Penelitian}

Dengan menggunakan metode pengujian instrument yang digunakan adalah pengujian validitas dan reliabilitas. Teknik analisis data yang digunakan adalah teknik deskriptif kuantitatif, analisis regresi linier sederhana dan uji t. Metode kuantitatif digunakan untuk meneliti pada populasi atau sampel tertentu, teknik pengambilan data umumnya dilakukan secara random, pengumpulan data menggunakan instrumen penelitian, analisis data bersifat statistik dengan tujuan untuk menguji hipotesis yang telah ditetapkan.

Metode survey itu sendiri digunakan untuk mendapatkan data dari tempat tertentu yang alamiah (bukan buatan), tetapi peneliti melakukan perlakuan pengumpulan data dengan mengedarkan kuesioner, test, wawancara terstruktur dan sebagainya (Sugiyono, 2010;11).

\section{Hasil Dan Pembahasan}

Analisis Statistik meliputi:

1. Uji Validitas

Validitas menunjukan sejauh mana suatu alat pengukur itu mengukur apa yang diukur. Menurut Sekaran (2006;133), "Korelasi product moment yaitu suatu alat ukur yang mengukur keterhubungan antara variabel independen dan variabel dependen. Alat ukur untuk melihat variabel yang digunakan dalam penelitian ini adalah korelasi Product Moment".

Kuesioner dari masing-masing item dinyatakan valid jika koefisien validitas lebih besar dari rtabel, yaitu 0,196. Berdasarkan dari tabel dibawah ini dari hasil uji pengolahan data dapat diketahui bahwa semua item dari pernyataan pada kuesioner dinyatakan validitas, karena rhitung > 0,196 maka semua pernyataan dapat digunakan sebagai alat pengumpulan data.

Tabel 1 Uji Validitas Variabel Iklan (X)

\begin{tabular}{|c|c|c|c|}
\hline \multirow[b]{2}{*}{ Pernyataan } & \multicolumn{3}{|c|}{ Iklan Televisi Shopee (X) } \\
\hline & rhitung & $\begin{array}{l}\text { rtabel } \\
\mathbf{n}=\mathbf{1 0 0}\end{array}$ & Keterangan \\
\hline 1 & 0,592 & 0,196 & Valid \\
\hline 2 & 0,633 & 0,196 & Valid \\
\hline 3 & 0,599 & 0,196 & Valid \\
\hline 4 & 0,699 & 0,196 & Valid \\
\hline 5 & 0,625 & 0,196 & Valid \\
\hline 6 & 0,732 & 0,196 & Valid \\
\hline 7 & 0,652 & 0,196 & Valid \\
\hline 8 & 0,698 & 0,196 & Valid \\
\hline
\end{tabular}




\begin{tabular}{cccc}
\hline 9 & 0,712 & 0,196 & Valid \\
\hline 10 & 0,631 & 0,196 & Valid \\
\hline 11 & 0,616 & 0,196 & Valid \\
\hline 12 & 0,673 & 0,196 & Valid \\
\hline 13 & 0,747 & 0,196 & Valid \\
\hline 14 & 0,741 & 0,196 & Valid \\
\hline
\end{tabular}

Sumber: Hasil Olahan Data (SPSS 22)

Nilai rhitung yang dihasilkan jauh lebih besar dari pada nilai rtabel yang ada untuk $\mathrm{n}=100$ ( Seratus ) yaitu 0.196 .

Tabel 2 Uji Validitas Variabel Brand Awareness (Y)

\begin{tabular}{cccc}
\hline \multirow{2}{*}{ Pernyataan } & \multicolumn{3}{c}{ Brand Awareness (Y) } \\
\cline { 2 - 4 } & rhitung & $\begin{array}{c}\text { rtabel } \mathbf{n} \\
\mathbf{= 1 0 0}\end{array}$ & Keterangan \\
\hline 1 & 0,732 & 0,196 & Valid \\
\hline 2 & 0,627 & 0,196 & Valid \\
\hline 3 & 0,559 & 0,196 & Valid \\
\hline 4 & 0,581 & 0,196 & Valid \\
\hline Sumber : Hasil Olahan Data (SPSS 22)
\end{tabular}

Nilai rhitung yang dihasilkan jauh lebih besar dari pada nilai rtabel yang ada untuk $\mathrm{n}=100$ (Seratus) yaitu 0.196.

2. Uji Reliabilitas

Menurut Sugiyono (2015:3203), Reliabilitas merupakan suatu konsistensi alat ukur dalam menghasilkan data, disebut konstan apabila data hasil pengukuran dengan alat yang sama dan berulang-ulang akan menghasilkan data yang relatif sama. Pengukuran yang mempunyai reliabilitas tinggi, yaitu pengukuran yang mampu memberikan hasil ukur yang terpercaya (reliable).

Tabel 3 Uji Reliabilitas Variabel Iklan (X)

$\frac{\frac{\text { Reliability Statistics }}{\text { Cronbach's Alpha N of Items }}}{\text { Sumber : Hasil Olahan Data (SPSS 22) }}$

Berdasarkan tabel di atas, untuk uji reliabilitas variabel Iklan Televisi (X) dengan nilai Cronbach's Alpha sebesar 0.904 berada di skor kisaran 0.800-1.000, sehingga dapat disimpulkan instrumen penelitian mengenai variabel Iklan Televisi (X) adalah Sangat Reliabel.

Tabel 4 Uji Reliabilitas Variabel Brand Awareness (Y)

\begin{tabular}{ll}
\multicolumn{2}{c}{ Reliability Statistics } \\
\hline Cronbach's Alpha & N of Items \\
\hline .440 & 4 \\
\hline
\end{tabular}

Sumber : Hasil Olahan Data (SPSS 22) 
Berdasarkan tabel di atas, untuk uji reliabilitas variabel Brand Awareness (Y) dengan nilai Cronbach's Alpha sebesar 0.440 berada di skor kisaran $0.400-0.599$, sehingga dapat disimpulkan instrumen penelitian mengenai variabel Brand Awareness (Y) adalah Cukup Reliabel.

3. Uji Normalitas

Tabel 5 Hasil Uji Normalitas

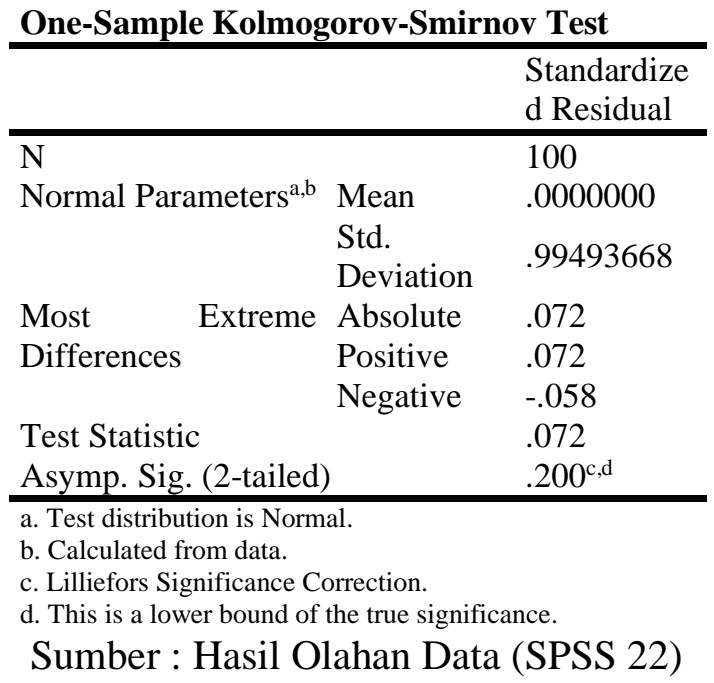

Berdasarkan hasil pengujian tabel diatas hasil pengujian One- Sample KolmogorovSmirnov Test menghasilkan asymptotic signivicance. Besar $\geq 0,05$ yaitu 0,200. Berdasarkan uji di atas bahwa model regresi telah memenuhi asumsi kenormalan.

4. Uji Heteroskedastisitas

\section{Grafik 1 Hasil Uji Heteroskedastisitas}

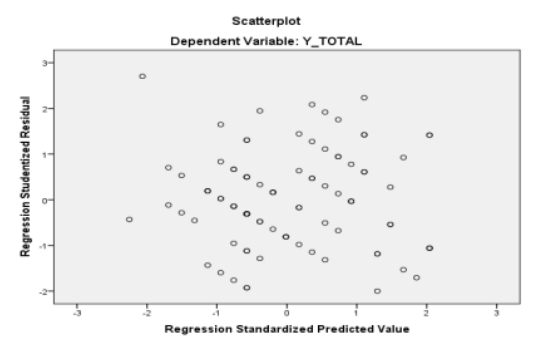

Sumber : Hasil Olahan Data (SPSS 22)

Berdasarkan pada gambar diatas hasil tidak terdapat pola yang teratur baik yang menyempit maupun bergelombang. Adapun titik pada sumbu Y, maka tidak terjadi heteroskedastisitas. 
5. Analisis Regresi Linear Sederhana

a. Hasil Analisis Regresi Linear Sederhana

Tabel 6 Hasil Analisis Regresi Linear Sederhana Coefficients $^{\mathrm{a}}$

\begin{tabular}{lll}
\hline & \multicolumn{2}{l}{$\begin{array}{l}\text { Unstandardized } \\
\text { Coefficients }\end{array}$} \\
\cline { 2 - 3 } Model & $\mathrm{B}$ & \multicolumn{1}{c}{ Std. Error } \\
\hline 1 (Constant) & 2.683 & 1.060 \\
IKLANTELEVISI & .207 & .023 \\
\hline a. Dependent Variable: BRANDAWARENESS \\
Sumber: Hasil Olahan Data (SPSS 22)
\end{tabular}

Berdasarkan pada tabel diatas, hasil dari analisis regresi linear sederhana dinyatakan dalam persamaan sebagai berikut :

$$
\mathrm{Y}=\mathbf{2 . 6 8 3}+\mathbf{0 . 2 0 7} \mathrm{X}
$$

b. Konstanta

Pada persamaan di atas nilai konstanta sebesar 2,683 yang berarti jika skor pada variabel iklan televisi sama dengan nol brand awareness akan sebesar 0,207.

c. Koefesiensi Regresi Iklan Televisi

Iklan televisi pada persamaan di atas diperoleh sebesar 0,207 yang berarti positif searah dan jika skor pada variabel iklan televisi meningkat maka brand awareness akan meningkat dan sebaliknya apabila skor variabel iklan televisi menurun maka brand awareness akan menurun, dengan asumsi variabel lain sama dengan nol atau dalam keadaan konstan.

\section{Tabel 7 Hasil Uji t}

Coefficients $^{\mathbf{a}}$

\begin{tabular}{|c|c|c|c|c|c|c|}
\hline \multirow{2}{*}{\multicolumn{2}{|c|}{ Model }} & \multicolumn{2}{|c|}{$\begin{array}{l}\text { Unstandardize } \\
\text { d Coefficients }\end{array}$} & \multirow{2}{*}{$\begin{array}{c}\begin{array}{c}\text { Standardized } \\
\text { Coefficients }\end{array} \\
\text { Beta }\end{array}$} & \multirow[b]{2}{*}{$\mathrm{t}$} & \multirow[b]{2}{*}{ Sig. } \\
\hline & & B & $\begin{array}{l}\text { Std. } \\
\text { Error }\end{array}$ & & & \\
\hline \multirow[t]{2}{*}{1} & (Constant) & 2.683 & 1.060 & & 2.531 & .013 \\
\hline & $\begin{array}{l}\text { IKLANTE } \\
\text { LEVISI }\end{array}$ & .207 & .023 & .667 & 8.869 & .000 \\
\hline
\end{tabular}

Sumber: Hasil Olahan Data (SPSS 22)

Dari hasil uji t pada tabel diatas, diketahui thitung sebesar 8,869 dan nilai ttabel pada d.f $=(n-k)=100-2=98$ dengan taraf signifikansi $(\alpha)=0,05$, yaitu sebesar 1,98447 karena thitung > ttabel, maka H0 ditolak artinya iklan televisi memiliki korelasi signifikan terhadap brand awareness.

\section{Kesimpulan}

Penelitian ini bertujuan untuk mengetahui apakah ada pengaruh iklan televisi Shopee terhadap Brand Awerenss Shopee di PT. Shopee International Indonesia Jakarta . Dari rumusan masalah yang telah dikemukakan pada bab sebelumnya dapat ditarik kesimpulan, yaitu berdasarkan analisis secara parsial (Uji t) hasil penelitian menunjukkan bahwa iklan televisi memiliki pengaruh terhadap terbentuknya brand awareness. 


\section{DAFTAR PUSTAKA}

Aaker, David. (1991). Managing Brand Equity; Capitalizing on the Value of Brand Name. New York: Free Press.

Ade Winata, (2017). Pengaruh Iklan Pada Media Televisi Terhadap Minat Beli (Studi Pada Calon Konsumen Bukalapak.com di Kota Denpasar). Skripsi Fakultas Ekonomi dan Bisnis Universitas Udayana, Bali, Indonesia.

Archie Fazira Rachmady (2012). Pengaruh Iklan Televisi Pocari Sweat Versi JKT-48 (Build The Dream) Terhadap Brand Image Pocari Sewat. Skripsi Fakultas Manajemen Bisnis Telekomunikasi \& Informatika Universitas Telkom.

Brigita Tri Winarsih, (2016). Analisis Pengaruh Daya Tarik Televisi Tokopedia Terhadap Brand Awareness. Skripsi Fakultas Ekonomi Universitas Sanata Dharma Yogyakarta.

Budiawan Budi Putranto, (2015). Analisis Pengaruh Iklan Dan Kredibilitas Endorser Terhadap Brand Awareness Untuk Meningkatkan Brand Attitude Produk Minuman Isotonik Merek Mizone. Skripsi Fakultas Ekonomika Dan Bisnis Universitas Diponegoro Semarang.

Dian Indah Zulastari, (2016). Pengaruh Citra Merek Bukalapak.com Terhadap Keputusan Pembelian Konsumen. Skripsi Fakultas Komunikasi dan Bisnis Universitas Telkom.

Durianto, Sugiarto, Widjaja, dan Supratikno. (2004). Invasi Pasar dengan Iklan yang Efektif. Jakarta: PT. Gramedia Pustaka Utama.

Fajar Agustyan, (2017). Pengaruh E-Commerce, Kualitas Produk Dan Brand Image Terhadap Keputusan Pembelian Pada Industri Ekonomi Kreatif. Skripsi Fakultas Ekonomi Dan Bisnis Universitas Lampung.

http://acommerce.co.id/ecomscape-2017-lanskap-ecommerce-indonesia-yang-selalu-berubah/

http://www.nielsen.com/id/en/press-room/2017/Tren-Baru-DiKalangan-Pengguna-InternetDi-Indonesia.html

http://perpi.or.id/perempuan-dan-geliat-e-commerce-di-indonesia/

Kefas Aldi Hartono, (2016). Pengaruh Daya Tarik Iklan Dan Selebriti Endorser Terhadap Kesadaran Merek Dan Dampaknya Terhadap Brand Attitude Minuman Dalam Kemasan. Skripsi Manajemen Fakultas Ekonomi Universitas Negeri Yogyakarta.

Khoirul Huda, (2013). Pengaruh Tayangan Iklan Televisi Terhadap Keputusan Pembelian Dengan Brand Image Sebagai Variabel Intervening Di Surabaya. Skripsi Sekolah tinggi Ilmu Ekonomi Indonesia (STIESIA) Surabaya.

Kotler, Phillip \& Armstrong, Gary (2008). Principles of Marketing, Jakarta: Rineka Cipta.

Kotler, Phillip \& Keller, Kevin. (2009). Marketing Management. New Jersey: Pearson Prentice Hall.

Kotler dan Keller. (2007). Manajemen Pemasaran. Edisi 12. Jilid 1. PT. Indeks: Jakarta. 
Kotler, Philip dan Kevin Lane Keller. (2009). Manajemen Pemasaran. Edisi Ke-13 Jilid 1 \& 2. Jakarta: Erlangga.

Lee, Monle \& Johnson, Carla. (2004) Prinsip - Prinsip Pokok Periklanan Dalam Perspektif Global. Jakarta: Kencana

Morissan, M. A. (2010). Periklanan Komunikasi Pemasaran Terpadu. Jakarta: Kencana Prenada Media Group.

Rangkuti, Freddy. (2008). The Power of Brands: Teknik Brand Equity dan Strategi Pengembangan Merek. Jakarta: PT. Gramedia Pustaka Utama

Sekaran, Uma. (2006). Metodologi Penelitian Untuk Bisnis. Jakarta: Salemba Empat.

Sugiyono. (2010). Metode Penelitian Bisnis. Bandung: Alfabeta.

Selly Ester, (2012). Analisis Pengaruh Iklan terhadap Brand Awareness". Penelitian ini bertujuan untuk melihat pengaruh dari iklan "Akses Internet Cepat XL. Program Studi Manajemen Pemasaran Jurusan Administrasi Niaga Politeknik Negeri Bandung.

Suharno \& Sutarso, Yudi. (2010). Marketing in Practice. Yogyakarta: Graha Ilmu.

Sunyoto, Dadang. (2011). Analisis Regresi dan Uji Hipotesis. Yogyakarta: CAPS.

www.shopee.com

Yuniska Hari Pramitadewi, (2009). Pengukuran kesadaran merek (brand awareness) pada produk Madurasa PT. Air Mancur. Skripsi Fakultas Ekonomi Universitas Sebelas Maret Surakarta. 